I. When mannite is dissolved in concentrated sulfuric acid it is dehydrated to the form $\mathrm{C}_{6} \mathrm{H}_{6} \mathrm{O}(\mathrm{OH})_{2}$, at the same time combining with the acid as the disulfuric acid ester.

2. At low temperatures there is produced mainly a levorotatory ester. At higher temperatures dextrorotatory compounds are produced togcther with derivatives which have partly lost their power to combine with acid groups.

3. In the presence of the higher fatty acids, esters are produced presumably with the above anhydride of mannite. During the processes of separation they become hydrated to mannid and mannitan forms.

\title{
THE EFFICIENCY OF THE PREPARATION OF ETHER FROM ALCOHOL AND SULFURIC ACID.
}

By P. N. Evans and Lena M. Sutton.

Received April 9, 1913.

The preparation of ethyl ether from alcohol and sulfuric acid has been the subject of much experiment and theoretical discussion since the discovery of the process in 1544 . The generally accepted theory at present is that ethyl sulfuric acid and water are first formed and that the ethyl sulfuric acid then reacts with more alcohol to form ether and sulfuric acid, in accordance with the equations:

$$
\begin{aligned}
& \mathrm{C}_{2} \mathrm{H}_{5} \mathrm{OH}+\mathrm{H}_{2} \mathrm{SO}_{4}=\mathrm{C}_{2} \mathrm{H}_{5} \mathrm{HSO}_{4}+\mathrm{H}_{2} \mathrm{O} \\
& \mathrm{C}_{2} \mathrm{H}_{5} \mathrm{HSO}_{4}+\mathrm{C}_{2} \mathrm{H}_{5} \mathrm{OH}=\mathrm{C}_{2} \mathrm{H}_{5} \mathrm{OC}_{2} \mathrm{H}_{5}+\mathrm{H}_{2} \mathrm{SO}_{4} .
\end{aligned}
$$

According to this theory the sulfuric acid acts only as a catalyst and a limited quantity should be capable of converting an unlimited amount of alcohol into ether and water. Experience has shown, however, that this is not the case, and various explanations have been offered of the limitations of the process.

It is often stated that the accumulation of the water formed in the first reaction so dilutes the sulfuric acid that it ceases to perform its function as catalyst. It is also considered by some that the sulfuric acid is slowly destroyed by other reactions, the chief of which is said to be its reduction to sulfur dioxide by the organic materials present.

The limit of reasonable efficiency is variously given; some writers state that the sulfuric acid can convert only three times its weight of alcohol into ether, others give somewhat higher figures.

The object of the work here reported was to determin experimentally the efficiency of the method, or the completeness of the reaction, during the progress of the preparation, to find the limit of reasonable efficiency, and to ascertain the cause of the final failure of the reaction.

\section{Experimental.}

Efficiency of the Process.--Several preliminary experiments were made in finding a satisfactory method of maintaining a fairly constant tempera- 
ture and uniform conditions, but it will suffice to describe the final arrangement, and to present in some detail the results of a normal preparation.

A half-liter distilling flask connected with a condenser was fitted with a thermometer graduated in fifths of a degree reaching to the bottom of the flask, and a dropping funnel extending below the neck of the flask and bent to the side so that the entering alcohol was delivered somewhat above the liquid and did not come in contact with the thermometer; the temperature was maintained throughout the experiment within five degrees and most of the time within two degrees of $140^{\circ}$. Twenty-five cubic centimeters each of ordinary concentrated sulfuric acid and alcohol of 91.4 weight per cent. strength were mixed in the flask, the temperature was raised to $140^{\circ}$, and alcohol of the same strength was then continuously introduced from the funnel. The distillate was caught in Ioo cc. fractions, each of which was then subjected to a gravity determination and then fractional distillation, the volume of total distillate being recorded at the end of each five-degree interval, with the following results:

\begin{tabular}{|c|c|c|c|c|c|c|c|c|c|c|c|}
\hline \multirow[b]{2}{*}{ No. } & \multirow[b]{2}{*}{ Gravity. } & \multicolumn{10}{|c|}{ Total distillate up to } \\
\hline & & 50. & 55. & 60. & 65. & 70. & 75. & 80. & 85. & 90. & 95 \\
\hline 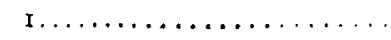 & 0.811 & o & $\mathbf{I}$ & 24 & 30 & 36 & 43 & 68 & 89 & 92 & 93 \\
\hline$\ldots \ldots, \ldots \ldots \ldots \ldots$ & 0.824 & o & $\mathrm{I}$ & 7 & 15 & 24 & $3 \mathrm{I}$ & 70 & $9 I$ & 93 & \\
\hline$\ldots \ldots \ldots \ldots \ldots \ldots$ & $0.82 \mathrm{I}$ & I & & & & & o & 80 & & & \\
\hline $4 \ldots \ldots \ldots \ldots \ldots \ldots \ldots$ & $0.82 \mathrm{I}$ & I & & 7 & & 23 & $\mathbf{I}$ & 79 & & 4 & \\
\hline $5, \ldots \ldots \ldots \ldots \ldots \ldots \ldots$ & $0.82 \mathrm{I}$ & $\mathbf{I}$ & 3 & Io & I8 & 25 & 4 & & & 4 & \\
\hline $6 \ldots \ldots \ldots \ldots \ldots \ldots \ldots$ & 0.824 & I & 3 & Io & 19 & 25 & 3 & 30 & & 4 & \\
\hline$\ldots \ldots \ldots \ldots \ldots \ldots \ldots$ & 0.819 & I & 5 & I3 & 20 & 27 & & 83 & I & 2 & \\
\hline .......... & 0.824 & I & 2 & 6 & 4 & 22 & 0 & 84 & 92 & 4 & \\
\hline$\ldots \ldots \ldots \ldots$ & 0.822 & I & I & 5 & & & o & 37 & & 3 & \\
\hline$\ldots \ldots \ldots \ldots \ldots \ldots$ & 0.820 & o & 2 & 6 & 6 & a & 0 & 85 & 13 & 15 & \\
\hline$I I \ldots \ldots \ldots \ldots$ & $0.82 \mathrm{I}$ & I & 3 & 8 & I6 & 4 & & & & & \\
\hline I2. $\ldots \ldots \ldots \ldots \ldots \ldots \ldots \ldots$ & 0.821 & $\mathbf{I}$ & & 9 & & & & & & & \\
\hline$\ldots \ldots \ldots \ldots \ldots \ldots \ldots$ & 0.822 & I & & 6 & & & & & & & \\
\hline$\ldots \ldots \ldots \ldots \ldots \ldots \ldots$ & 0.824 & I & & 7 & & & & & & 4 & \\
\hline I $5 \ldots \ldots \ldots \ldots \ldots \ldots \ldots \ldots \ldots$ & 0.820 & 0 & I & 3 & & & & & & 4 & \\
\hline $16 \ldots \ldots \ldots \ldots$ & $0.82 \mathrm{I}$ & I & 2 & 5 & & $2 \mathbf{I}$ & o & 84 & 4 & 94 & \\
\hline I 7. & 0.820 & I & 2 & 7 & & & & 84 & & 5 & \\
\hline $18 \ldots \ldots \ldots \ldots$ & 0.821 & o & 2 & 7 & 14 & & o & 85 & 3 & 4 & \\
\hline $19 \ldots \ldots \ldots \ldots$ & 0.821 & $\mathbf{I}$ & 3 & 7 & & & & & & & \\
\hline 20. & 0.824 & o & 2 & 4 & & & & 4 & & & \\
\hline $21 .$. & $0.82 \mathrm{I}$ & o & 2 & 4 & I & I & & & & & \\
\hline$\cdots \cdots \cdots$ & $0.82 \mathrm{I}$ & 0 & 2 & 5 & & & & 7 & & & \\
\hline & 0.819 & 0 & 2 & & & & & & & & \\
\hline & 0.8 & 0 & I & 4 & & & & & & & \\
\hline & & 8 & 12 & 4 & & & & & & & \\
\hline & & 2 & 8 & 17 & & & 36 & 72 & 9 & I & 94 \\
\hline & & 2 & 8 & I7 & & & & & 0 & 92 & \\
\hline 8. & 0.828 & 3 & 5 & I4 & $2 \mathrm{I}$ & 27 & 34 & 69 & $9 \mathrm{I}$ & 93 & 95 \\
\hline
\end{tabular}




\begin{tabular}{|c|c|c|c|c|c|c|c|c|c|c|c|}
\hline \multirow[b]{2}{*}{ No. } & \multirow[b]{2}{*}{ Gravity. } & \multicolumn{10}{|c|}{ Total distillate up to } \\
\hline & & 50. & 55. & 60. & 65. & 70. & 75. & 80. & 85. & 90. & 95 \\
\hline$\ldots$ & $0.83 \mathrm{I}$ & 3 & 12 & $2 \mathrm{I}$ & 27 & 33 & 38 & 65 & 89 & 91 & \\
\hline$o \ldots \ldots \ldots \ldots \ldots \ldots \ldots$ & $0.83 \mathrm{I}$ & 3 & I3 & 20 & 27 & 3 & & 65 & 89 & 2 & 34 \\
\hline $31, \ldots \ldots \ldots \ldots, \ldots, \ldots$ & $0.83 \mathrm{I}$ & 3 & I3 & $2 \mathrm{I}$ & 28 & 33 & & 63 & 89 & & 93 \\
\hline $32 \ldots \ldots \ldots \ldots \ldots \ldots \ldots$ & 0.834 & 2 & 8 & I7 & 24 & 30 & 3 & 65 & 89 & & 94 \\
\hline $33 \ldots \ldots \ldots \ldots \ldots \ldots \ldots$ & 0.829 & 5 & 12 & 20 & 27 & 32 & 8 & 68 & 89 & 2 & 94 \\
\hline$\cdots$ & 0.829 & 2 & 8 & I5 & 22 & 29 & 6 & 74 & o & & 95 \\
\hline$\ldots \ldots \ldots \ldots \ldots \ldots \ldots$ & 0.826 & o & 5 & I5 & 23 & 30 & 8 & 65 & 90 & 2 & 95 \\
\hline ........ $>$ > 251 & 0.831 & 0 & I & I 4 & 22 & $3 \mathrm{I}$ & 38 & 63 & 90 & & 95 \\
\hline$\cdots$ & $0.83 \mathrm{I}$ & o & o & I 2 & $2 \mathrm{I}$ & 27 & & 67 & $9^{2}$ & & 95 \\
\hline$\cdot$ & 0.829 & 0 & 3 & I3 & 21 & 28 & 30 & 68 & 93 & & 95 \\
\hline$\ldots \ldots$ & 0.829 & 2 & 4 & I I & 19 & 25 & 33 & 73 & 89 & I & 93 \\
\hline$\ldots \ldots \ldots \ldots \ldots \ldots \ldots \ldots$ & 0.829 & o & 2 & I 2 & I9 & 26 & 33 & 75 & $9 \mathbf{I}$ & 2 & 95 \\
\hline$\ldots \ldots \ldots \ldots \ldots \ldots \ldots, \ldots$ & 0.824 & o & 2 & 8 & 17 & 24 & 32 & 86 & 93 & 4 & 95 \\
\hline$\cdots \cdots$ & 0.824 & 3 & 8 & I6 & 23 & 29 & 35 & 77 & 92 & 94 & 95 \\
\hline$\ldots$ & 0.825 & 3 & 5 & I I & 18 & 25 & & 72 & 92 & & 95 \\
\hline 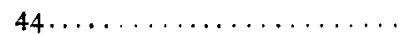 & & 2 & 4 & Io & 16 & 22 & 28 & 62 & 83 & 86 & 87 \\
\hline
\end{tabular}

Interruptions of several days were necessary after the $24^{\text {th }}, 34^{\text {th }}$, and 42nd fractions (marked), and the process was discontinued during the $44^{\text {th }}$ because it was found impossible to regulate the temperature and practically no liquid remained in the flask. The total time of heating was about 13 hours.

Inspection of these results shows some variability among the distillates, as might be expected from unavoidable variations in temperature during the generation and in rate of distillation during the fractionation; no steady trend, however, is to be observed, the later averaging about the same as the earlier figures for any temperature interval.

To deduce from these results of fractionation the efficiency of the preparation, mixtures of ether, alcohol, and water were made in the proportions to be expected from different degrees of completeness of the original reaction:

$$
{ }_{2} \mathrm{C}_{2} \mathrm{H}_{5} \mathrm{OH}=\mathrm{C}_{2} \mathrm{H}_{5} \mathrm{OC}_{2} \mathrm{H}_{5}+\mathrm{H}_{2} \mathrm{O} \text {. }
$$

The assumption was made that the residue in the generating flask remained. unchanged in quantity and proportions during the production of each distillate, and that therefore the latter consisted of the ether formed, the alcohol introduced but not decomposed, and the. water formed in the reaction and that introduced with the alcohol, which was of 91.4 weight per cent. strength, as calculated from its specific gravity 0.820 at $22^{\circ}$.

For example, if the completeness of reaction be $100 \%$ the alcohol is entirely converted into ether and water, and for every $100 \mathrm{cc}$. of strong alcohol introduced, weighing 82 grams, there is present $0.914 \times 82$ or 75 grams of pure alcohol, and $0.086 \times 82$ or 7 grams of water; from 75 grams of alcohol there is formed 60 grams of ether and 15 grams of water, which with the 7 grams of water present in the original alcohol gives 22 grams of 
water. The nearest whole numbers were taken. The distillate would therefore contain 60 grams of ether, o gram of alcohol, and 22 grams of water for every $100 \mathrm{cc}$. of strong alcohol introduced.

Calculated for less degrees of completeness of reaction, the proportion of ether in the distillate decreases, that of alcohol increases, and that of water decreases. The results expressed for intervals of $10 \%$ in the completeness are given in the following table, expressed as relative weights:

$\begin{array}{cccc}\begin{array}{c}\text { Completeness. } \\ \text { Per cent. }\end{array} & \text { Fther. } & \text { Alcohol. } & \text { Water. } \\ \circ & 0 & 75 & 7 \\ \text { 10 } & 6 & 68 & 8 \\ 20 & 12 & 60 & 10 \\ 30 & 18 & 53 & \text { I I } \\ 40 & 24 & 45 & 13 \\ 50 & 30 & 38 & 14 \\ 60 & 36 & 30 & 16 \\ 70 & 42 & 23 & 17 \\ 80 & 48 & 15 & 19 \\ 90 & 54 & 8 & 20 \\ 100 & 60 & 0 & 22\end{array}$

Mixtures were made up from materials of known purity corresponding to these proportions and fractionated like the distillates from the ether preparation, with the following results.

\begin{tabular}{|c|c|c|c|c|c|c|c|c|c|c|c|c|}
\hline $\begin{array}{l}\text { ompleteness. } \\
\text { Per cent. }\end{array}$ & 40. & 45. & 50. & 55. & 60. & 65. & 70. & 75. & 80. & 85. & 90. & 95. \\
\hline o..... & . & . & . & . & . & . & . & 0 & $5^{2}$ & 77 & $9 I$ & 97 \\
\hline 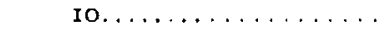 & . & . & . & . & . & 0 & 2 & I I & 81 & 92 & 97 & 99 \\
\hline $20 \ldots$ & . & . & . & o & $\mathbf{I}$ & 5 & I5 & 22 & 9 I & 97 & 98 & 99 \\
\hline $30 \ldots \ldots$ & . & . & 0 & 2 & 7 & I6 & 24 & 32 & 89 & 95 & 96 & 98 \\
\hline $40 \ldots \ldots \ldots \ldots \ldots \ldots$ & . & 0 & I & 8 & 18 & 26 & 34 & 42 & 83 & 87 & 92 & 95 \\
\hline $50 \ldots \ldots \ldots \ldots \ldots$ & o & I & 9 & 20 & 30 & 36 & 41 & 48 & 74 & 90 & 92 & 94 \\
\hline $60 \ldots \ldots \ldots \ldots \ldots \ldots$ & o & 6 & 24 & 35 & $4 \mathrm{I}$ & 46 & 50 & 55 & 67 & $8 I$ & 90 & 92 \\
\hline $70 \ldots \ldots \ldots \ldots \ldots$ & $\mathbf{o}$ & 27 & 40 & 46 & $5 I$ & 55 & $5^{8}$ & 60 & 64 & 80 & 86 & 89 \\
\hline $80 \ldots \ldots \ldots \ldots \ldots \ldots$ & 13 & 44 & $5 \mathrm{I}$ & 59 & 62 & 64 & 65 & 67 & 68 & 76 & 83 & 86 \\
\hline $90 \ldots \ldots \ldots \ldots \ldots \ldots$ & 54 & 68 & 70 & 71 & 71 & 72 & 72 & 73 & 73 & 74 & 78 & 82 \\
\hline $100 \ldots \ldots \ldots \ldots$ & 32 & 72 & 77 & 77 & 78 & 78 & 78 & 78 & 78 & 78 & 78 & \\
\hline
\end{tabular}

While it is not to be expected, in view of the experimental inaccuracies of fractional distillation, that perfect agreement should be found between the actual distillates and the artificial mixtures, inspection of the results shows that throughout the preparation the composition of the distillates indicated a completeness of between 30 and $40 \%$, and in spite of fluctuations this value was approximately maintained throughout. The first distillate and those (No. 26 to 34 ) after the first interruption indicated a completeness between 40 and $50 \%$, but there was no gradual decline in efficiency towards the end. This will be seen from the following averages: 


\begin{tabular}{|c|c|c|c|c|c|c|c|c|c|c|c|c|}
\hline $\begin{array}{l}\text { Averages. } \\
\text { Number. }\end{array}$ & 45. & 50. & 55. & 60. & 65. & 70. & 75. & 80. & 85. & 90. & 95. & $\begin{array}{l}\text { Completeness. } \\
\text { Pet cent. }\end{array}$ \\
\hline I to 44 & 0 & I & 4 & I I & I 8 & 26 & 33 & 77 & 91 & 93 & 95 & 30 to 40 \\
\hline 2 to 24 & o & I & 2 & 6 & I4 & 22 & $3 I$ & 84 & 93 & 94 & 95 & 30 to 40 \\
\hline 26 to 34 & o & 3 & ro & I 8 & 25 & $3 I$ & 35 & 68 & 89 & 92 & 94 & 40 to $5^{\circ}$ \\
\hline 35 to 42 & 0 & I & 3 & 13 & $2 \mathrm{I}$ & 27 & 34 & 72 & $9 I$ & 93 & 94 & 30 to 40 \\
\hline 43 to 44 & o & 2 & 4 & IO & I 7 & 23 & 30 & 67 & 87 & 89 & $9 x$ & 30 to 40 \\
\hline
\end{tabular}

Yield of Ether.-Considering now the quantity of ether obtained from the sulfuric acid in this experiment, $25 \mathrm{cc}$. of concentrated acid were employed, weighing 46 grams; the total distillate measured 4400 cc., each $100 \mathrm{cc}$. contained about 22 grams of ether, the total yield of ether being about 968 grams, or 24 times the weight of the acid employed.

Residue in the Generating Flask.-At the conclusion of several preparations it was found that when the formation of ether abruptly came to an end there remained in the generating flask only one or two grams of a black and nearly solid material, when $25 \mathrm{cc}$. or 46 grams of sulfuric acid had been used. The reaction therefore does not cease on account of an accumulation of any material, such as water (as so often stated), but apparently because of the absence of sulfuric acid.

Formation of Sulfur Dioxide.-In order to determin the quantity of sulfur dioxide formed the distillate was delivered below the surface of water, or of the distillate, kept colored with bromine to convert any sulfur dioxide into sulfuric acid, and the distilling apparatus was then swept out by aspiration of air. The total distillate was then redistilled up to 80 , and the residue titrated with standard barium chloride and potassium chromate solutions according to the Wildenstein method.

The results of one experiment were as follows: Twenty-five cubic centimeters of pure sulfuric acid were treated with redistilled alcohol; the reaction come to an abrupt end when about $\mathrm{I} 600 \mathrm{cc}$. of distillate had passed over, the time required being seven hours, with one interruption. The residue from the redistillation was diluted to I liter and 25 -cc. portions were titrated, requiring $7.35 \mathrm{cc}$. of fourth-molar barium chloride solution. The whole amount of sulfuric acid lost as sulfur dioxide was therefore equivalent to 7.20 grams out of the 46 grams used, or $15 \%$.

Another experiment was made to determin the rate of formation of sulfur dioxide when a mixture of alcohol and sulfuric acid is kept at I4O, air being bubbled through. A mixture of $25 \mathrm{cc}$. of each substance was maintained at this temperature for 47 hours with ten interruptions, and a slow current of air passed through the mixture and then through water colored with bromine, the water being replaced and titrations made every half-hour during the heating. The results need not be given in detail but showed a fairly uniform production of sulfur dioxide equivalent in all to I I. 78 grams of sulfuric acid, or $25.6 \%$ of that employed in the experiment. The relative rates are shown by the total titrations for consecu- 
tive 5 -hour periods; $37.2,75.8,65.0,50.2,46.6,45.4,39.6,45.2,49.8$, and 50.4 cc. The rate of formation of sulfur dioxide here is decidedly slower than during the preparation of ether, about $25 \%$ of the acid being reduced in 47 hours in this case, and about $15 \%$ in 7 hours in the ether preparation.

Effect of Water on the Reaction.-In order to test the hypothesis so of ten presented that the accumulation of the water formed in the reaction is the inhibiting factor that finally brings it to an end, a mixture of $25 \mathrm{cc}$. each alcohol and sulfuric acid and roo cc. of water were placed in the generating flask, the temperature raised to $140^{\circ}$, considerable liquid distilling over, and then alcohol admitted as usual. The distillates gave on fractionation the following results, the first $93 \mathrm{cc}$. being that obtained before the temperature reached $140^{\circ}$, and evidently consisting largely of water; the others were roo-cc. distillates, and an interruption after the sixth showed the usual result indicating some formation of ether during the interval at ordinary temperature:

\begin{tabular}{|c|c|c|c|c|c|c|c|c|c|c|}
\hline No. & 50. & 55. & 60. & 65. & 70. & 75. & 80. & 85. & 90. & 95. \\
\hline $1 \ldots \ldots \ldots$ & . & $\cdots$ & . & . & . & . & $\ldots$ & $\circ$ & 15 & 29 \\
\hline $2, \ldots \ldots \ldots$ & $\mathbf{I}$ & 2 & 4 & 9 & I3 & 17 & 26 & 66 & $7^{6}$ & 81 \\
\hline $3 \ldots \ldots \ldots$ & o & 4 & I4 & 23 & 30 & 39 & 57 & 87 & 90 & 92 \\
\hline $4, \ldots \ldots \ldots$ & o & 7 & I7 & 22 & $3 I$ & 38 & 62 & 86 & 90 & 92 \\
\hline $5 \ldots \ldots \ldots$ & 0 & 7 & 14 & 23 & 29 & 39 & 57 & 85 & 90 & 93 \\
\hline $6 \ldots \ldots \ldots$ & 2 & 7 & 16 & 28 & 32 & 38 & 58 & 86 & $9 I$ & 93 \\
\hline $7 \ldots \ldots \ldots$ & 6 & I 8 & 24 & 28 & 35 & 40 & 52 & 79 & 81 & 84 \\
\hline $8 \ldots \ldots \ldots$ & 0 & I 2 & 22 & 25 & 33 & 40 & 54 & 87 & 90 & 93 \\
\hline $9 \ldots \ldots \ldots$ & o & 8 & 17 & 24 & 33 & 40 & 58 & 86 & 90 & 93 \\
\hline ro......... & o & 7 & 16 & 24 & 30 & 38 & 55 & 87 & 90 & 92 \\
\hline II........ & o & 7 & 17 & 23 & $3 I$ & 37 & 57 & 86 & 89 & 92 \\
\hline $12 \ldots \ldots \ldots$ & 2 & 9 & 17 & 25 & 30 & 37 & 62 & 87 & 90 & 9.1 \\
\hline
\end{tabular}

These figures indicate a completeness of about $40 \%$ in the original reaction, about the same as when concentrated acid was employed. "The distillation was continued without further examination of the distillates until $2300 \mathrm{cc}$. had distilled over and the reaction came to an end with a black residue weighing only I gram remaining.

The normal progress of this preparation when highly diluted sulfuric acid was used shows that the water formed in the reaction does not accumulate at the temperature employed so as to interfere with its usual degree of completeness.

Other By-products Containing Sulfur.-Some preliminary experiments were made to determin the other by-products, but the work had to be discontinued. It has now been resumed and it is hoped will form the subject of a subsequent report.

Conclusions.

1. The completeness of the conversion of alcohol into ether was found to be nearly $40 \%$. 
2. This efficiency was maintained in some experiments until the distillate amounted to as much as I 76 times the original volume of sulfuric acid, or till the ether produced reached 40 times the volume or 16 times the weight of acid used.

3. The efficiency fell off abruptly when there remained in the generating flask a charred and semi-solid residue weighing only about one-twentieth as much as the original acid.

4. The decrease in efficiency is not due to accumulation of water, for the reaction proceeds normally when dilute sulfuric acid is employed.

5. From $\mathrm{I}_{5}$ to $20 \%$ of the sulfuric acid used could be accounted for as sulfur dioxide.

PURdUE UNTVESITY, LAFAYETTE, INDIANA.

\title{
DISSOCIATION CONSTANT OF WEAK ACIDS AND BASES FROM SOLUBILITY DATA.
}

\author{
By Nilratan Dhar. \\ Received March 25, 1913.
}

It is well known that magnesium hydroxide is markedly more soluble in solutions of ammonium chloride than in pure water, and according to a current explanation ${ }^{1}$ this is due to the combination of the ammonium and hydroxyl ions which are brought together. The smallness of the dissociation constant of ammonium hydroxide involves the removal of a considerable quantity of hydroxyl ions in this way, and the quantity so removed must be made good by the solution of more solid magnesium hydroxide. Similarly much more calcium hydroxide dissolves in a solution of ammonium chloride than in pure water. ${ }^{2}$

Thus it is evident that a base will dissolve in greater amount in a solution of a salt of a weak base and a strong acid. Now assuming the dissociation constant of the dissolving base, the calculation of the dissociation constant of the base of which the salt is taken, is possible.

Exactly in the same way, the solubility of an acid is increased by the addition of a neutral salt solution of a weak acid and a strong base to it.

Thus much more benzoic acid dissolves in a solution of sodium acetate than in the same volume of water at the same temperature.

Since in the acetate solution, there is hydroxide ion $\left(\mathrm{OH}^{\prime}\right)$ (due to hydrolysis) which combines with the hydrogen ion $\left(\mathrm{H}^{\cdot}\right)$ of the acid, forming water and also benzoate ion is formed at the same time. Moreover, benzoic acid partly decomposes the sodium acetate solution and the following reaction takes place:

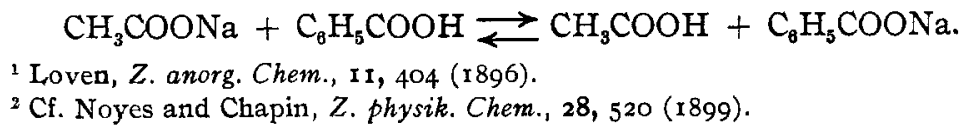

